\title{
On the Surface Independent Signals Within the ENSO Events
}

\author{
Mingqiang Fang \\ Ocean Remote Sensing Institute, Ocean University of China, Qingdao, China
}

\section{Email address:}

fmq@ouc.edu.cn

\section{To cite this article:}

Mingqiang Fang. On the Surface Independent Signals Within the ENSO Events. Earth Sciences. Vol. 7, No. 3, 2018, pp. $124-137$. doi: $10.11648 /$ j.earth.20180703.14

Received: May 16, 2018; Accepted: May 31, 2018; Published: June 13, 2018

\begin{abstract}
By analyzing the two types of El Niño Southern-Oscillation (ENSO) indices, i.e., the Central Pacific (CP) type index and the Eastern Pacific (EP) type index by Ren and Jin (2011), this study finds that the low correlation between the two types of indices by some previous studies should be reconsidered. Then based on previous ideas of the unified Niño index systems, the new ocean surface regions for the CP and EP El Niño indices' calculation are defined. The features of the new CP and EP El Niño indices are consistent with sea surface temperature anomaly (SSTA) evolution along the Pacific equator. This study suggests that, concerning the El Niño characteristics, the CP and EP El Niño indices are not necessarily independent of each other; but their differences are almost absolutely independent of the unified Niño region SSTA. The results quantitatively confirm the relationship between the Trans-Niño Index (TNI) and Niño 3.4 indices (which are nearly independent of each other and provide different flavors for each El Niño event). Results presented here contribute to a better understanding of the nature of the El Niño events.
\end{abstract}

Keywords: Unified Niño Regions, Thermal Centroid, ENSO, Central Pacific, Eastern Pacific

\section{Introduction}

Traditionally, it is suggested that an El Niño event occurs when 5-month running means of SST anomalies in the Niño 3.4 region $\left(5^{\circ} \mathrm{N}-5^{\circ} \mathrm{S}, 120^{\circ}-170^{\circ} \mathrm{W}\right)$ exceed $0.4^{\circ} \mathrm{C}$ or SST anomalies in the Niño 3 region $\left(5^{\circ} \mathrm{N}-5^{\circ} \mathrm{S}, 90^{\circ}-150^{\circ} \mathrm{W}\right)$ exceed $0.5^{\circ} \mathrm{C}$ for more than a certain number of months (Trenberth, 1997; Trenberth et. al, 2001). Most of currently existing Niño indices are based on the region coverage of the Niño 3, Niño 4, Niño 3.4, Niño 1+2 (Trenberth, 1997; Trenberth et. al, 2001; Trenberth and Stepaniak, 2001; Trenberth and Smith, 2006) and even recently merging indices such as the CP and EP indices are also strongly related to these Niño regions (Ashok et al., 2007; Kug et al., 2009; Yeh et al., 2009; Ren and Jin, 2011).

Trenberth and Stepaniak (2001) suggested the Trans-Niño index (TNI), which is based on the difference between normalized SST anomalies averaged in the Niño-1+2 and Niño-4 regions, to describe the character and evolution of the El Niño events. At the same time, they found that the Niño 3.4 index and TNI are nearly orthogonal. Recent studies show that a different kind of El Niño has happened more frequently since 1990 when warm SSTs in the central Pacific were flanked on the east and west by cooler SSTs (Larkin and Harrison, 2005; Ashok et al., 2007; Yeh et al., 2009; Kug et al., 2009; Xiang et al., 2012; Fang et al., 2013; Zheng et al., 2014). Several studies show that locations of maximum temperature anomaly are important indicators of El Niño events (Kao and Yu, 2009; Yu et al., 2011; Fang et al., 2013; Takahashi and Dewitte, 2015). Nearly all the studies show that among different kinds of El Niño events, location difference of maximum temperature anomalies can reach more than $50^{\circ}$ along the Equator (Yu et al., 2011; Yeh et al., 2009; Kao and Yu, 2009; Fang et al., 2013; Takahashi and Dewitte, 2015), presenting different flavor for each event.

According to the facts that the ocean surface areas with maximum temperature anomaly are different for El Niño events, Fang et al. (2013) suggested a unified Niño region (UNR) outlined by the $0.7^{\circ} \mathrm{C}$ contour line of the temporal SSTA standard deviation along the Pacific equator and showed that all the traditional Niño indices can be well rebuilt by simple linear combination of the mean SST anomaly and the zonal thermal centroid (ZTC) anomaly of the UNR with highly linear correlation. The ZTC anomaly agrees quite well 
with the EP/CP El Niño classification by Yeh et al., 2009 or Kug et al., 2009 and the TNI index by Trenberth and Stepaniak (2001).

The Niño-3 index and Niño-4 index are often concerned in the EP/CP El Niño classification (Kug et al., 2009; Yeh et al., 2009; Ren and Jin, 2011). The differences between these two indices are often considered in the EP/CP El Niño classification (Kug et al., 2009; Yeh et al., 2009). Although the Niño-3 index and Niño-4 index are used to describe the different types of CP or EP El Niño events, they are actually highly correlated to each other (Ren and Jin, 2011).

Trenberth and Stepaniak (2001) proposed the TNI index (regarded approximately as the SSTA gradient along the Pacific equator) and demonstrated the capabilities of the TNI index in describing different characters of each El Niño event. The TNI index shows that the SSTA gradient along the Pacific equator during the El Niño events is a fundamental feature of the El Niño events. The SSTA differences between the different Niño regions along the Pacific equator during the El Niño events, to a great extent, show the different flavors of El Niño events.

However, to decrease the correlation between the CP or EP indices, Ren and Jin (2011) proposed a new way of defining the CP and EP indices (see Equ. (1)). Their CP and EP indices are little correlated, which could lead to the implication that the CP Niño index and the EP Niño index are almost independent of each other. As mentioned above, Trenberth and Stepaniak (2001) found that the Niño 3.4 index and TNI are nearly orthogonal. The sensitivity of the eastern-western SSTA gradient needs to be further examined to ascertain if it is consistent with the physical nature of the CP/EP indices proposed by Ren and Jin (2011). And what are truly the independent factors associated with El Niño events need to be object of further investigations.

This study firstly investigates the background of the CP and EP indices' definitions of Ren and Jin (2011) and the calculation shows that their index system is, in nature, a result of searching for a zero correlation between $\mathrm{CP}$ and EP indices by linearly fitting CP and EP indices to Niño-3 and Niño-4 indices. Then, based on the work by Fang et al. (2013), this study shows that the differences between our new CP/EP indices and the mean SSTA within the UNR are nearly absolutely independent of each other. Results suggest that the fundamental independent features of the El Niño events are the group features of the Niño region mean SSTA and the zonal SSTA gradient, which were already similarly established by Trenberth and Stepaniak (2001) with their TNI and Niño-3.4 indices. The new CP and EP index system represents an improved version of the traditional systems associated with the TNI and Niño-3.4 group by Trenberth and Stepaniak (2001). The CP and EP region warming rates are also examined.

\section{Data}

The Optimum Interpolation Sea Surface Temperature Analysis (OISST) by NOAA is used here for the Niño indices' calculation, signal analysis and the new $\mathrm{CP}$ and EP region definition test. This SST analysis is mapped on a $1 \mathrm{x} 1$-degree grid monthly from Nov.1981 to Sept. 2014. Data between Oct.2014 to Feb.2017 were used to validate the new CP and EP region definitions. Satellite SST data, incorporated in the dataset, are adjusted for biases by using the methods of Reynolds (1988) and Reynolds and Marsico (1993) [(for further details see also Reynolds and Smith (1994)]. The indices presented here are not standardized.

\section{Methods}

\subsection{Statistical Analysis of the EP/CP Indices by Ren and Jin (2011)}

Previous studies show that the CP and EP types of El Niño events can co-exist, and this feature contributes to the high correlation detected between the CP and EP indices (Bejarano and Jin, 2008; Kug et al., 2009; Yeh et al., 2009; Kug et al., 2010; Yu and Kim, 2013; Ren et al., 2013: Capotondi et al., 2014; Zheng et al., 2014; Takahashi and Dewitte, 2015). Nevertheless, Ren and Jin (2011) suggested a set of CP and EP indices little correlated; in detail, they presented two new Niño indices using only Niño-3 and Niño-4 indices with a piecewise linear transformation:

$$
\left\{\begin{array}{l}
\mathrm{EP}_{\text {R.J. }}=N_{3}-\text { alpha } \times N_{4} \\
\mathrm{CP}_{R . J .}=N_{4}-\text { alpha } \times N_{3}
\end{array}, \quad\left\{\begin{array}{c}
\text { alpha }=2 / 5, N_{3} N_{4}>0 \\
\text { alpha }=0, \text { otherwise }
\end{array}\right.\right.
$$

where $N_{3}$ and $N_{4}$ denote Niño-3 and Niño-4 indices respectively. The EP and CP indices by Ren and Jin (2011) are shown in Figure 1.

Ren and Jin (2011) choose the fractional value $2 / 5$ for the coefficient alpha without giving a reasonable explanation. Figure 2 shows how the correlation between the $\mathrm{EP}_{R . J}$. and $\mathrm{CP}_{R . J \text {. }}$ indices in Equ. (1) varies when different alpha values are chosen. When alpha is chosen as 0.45 , the correlation between the $\mathrm{EP}_{R . J}$. and $\mathrm{CP}_{R . J}$. time series given by Equ. (1) goes to zero (the reason why Ren and Jin (2011) didn't select a proper alpha to make their correlation zero is not understandable). The EP and CP indices by Equ. (1) but with alpha $=0.45$ are plotted in Figure 1 in black. It shows clearly that the two sets of indices are actually identical (with simultaneous correlation both higher than 0.99 while the correlation coefficients at the 0.95 confidence level with the numbers of degrees of freedom estimated as in Trenberth (1984) is only about 0.45 ). This could indicate that Ren and Jin (2011) were technically establishing the CP/EP index system of low correlation by Equ. (1). 

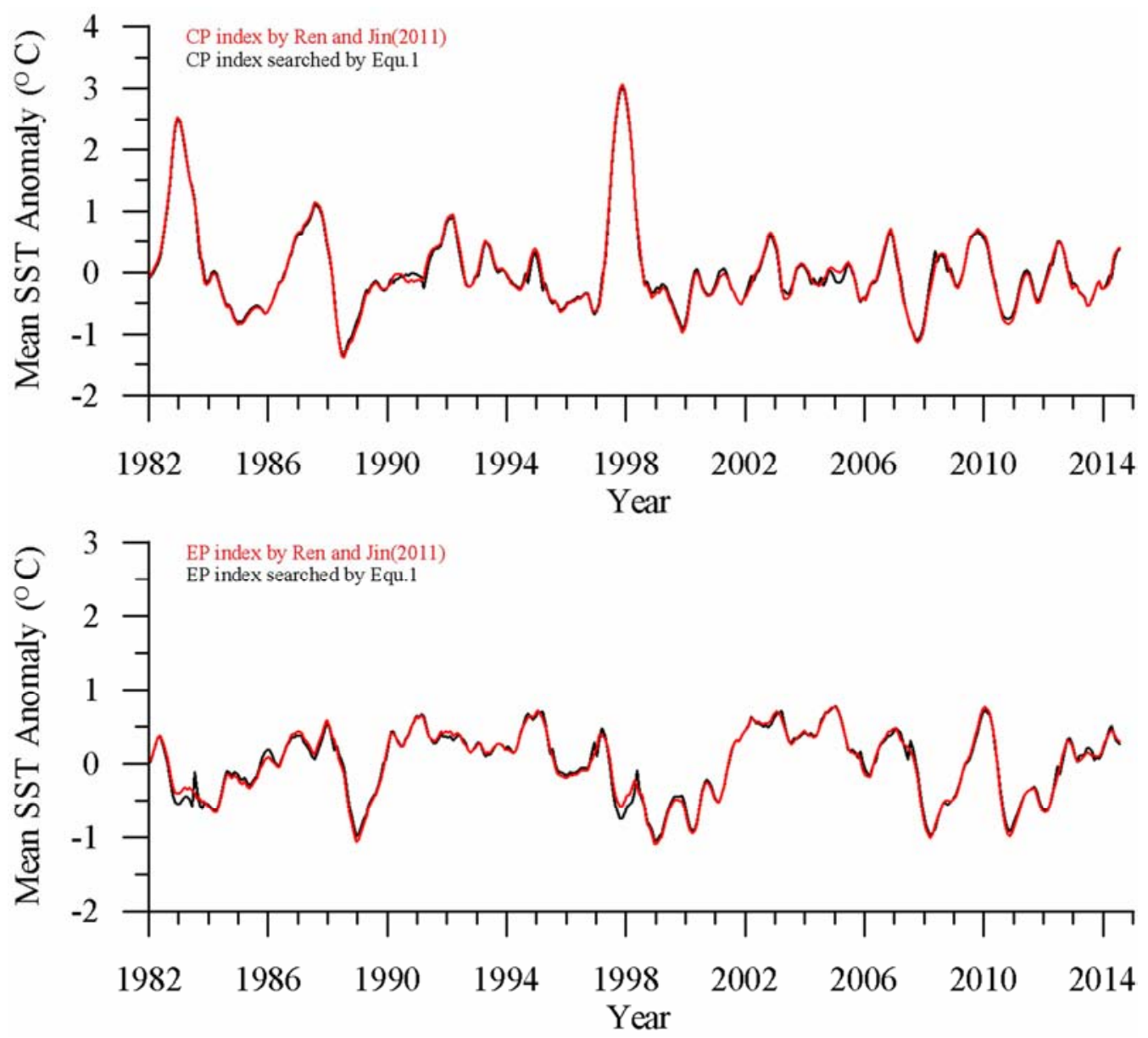

Figure 1. Comparison between the indices by Ren and Jin (2011, with alpha $=2 / 5$ in Equ. (1)) and the indices produced by Equ. (1) (but with alpha $=0.45$ when the correlation is nearly zero). The correlation coefficients at the 0.95 confidence level of all the signal pairs presented in this study are all between 0.40 and 0.55 so this confidence level information will not be repeated hereafter.

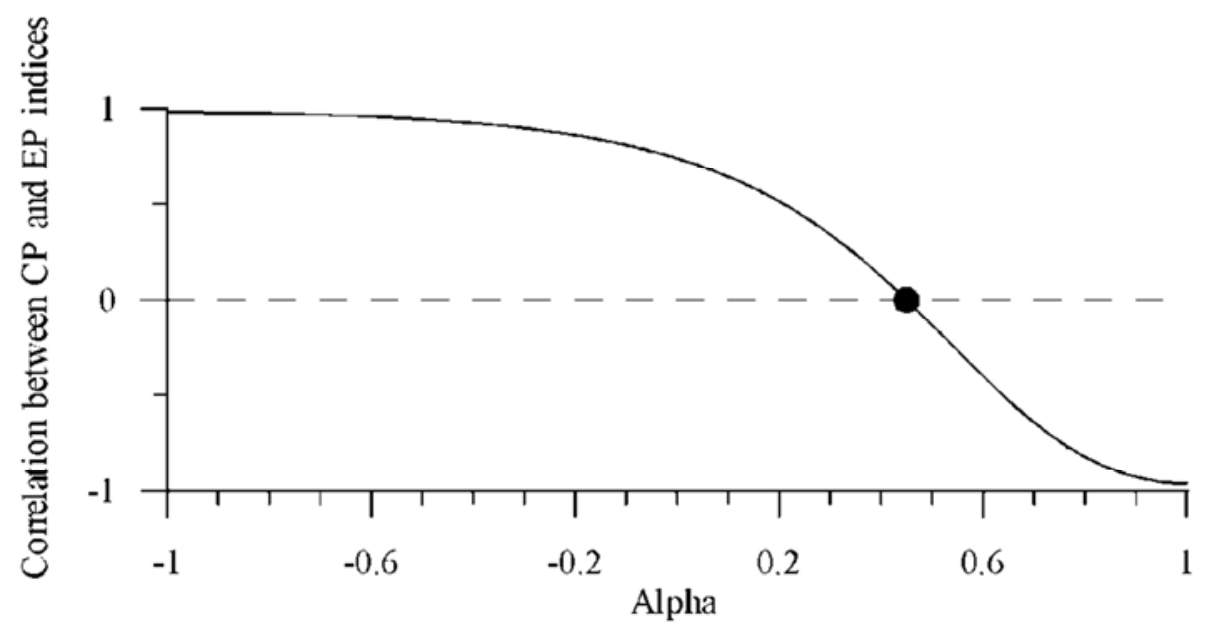

Figure 2. Correlation between the CP and EP index derived from Equ. (1) with different alpha. When alpha $\approx 0.45$, the correlation coefficient meets zero.

Ren and Jin (2011) stated that $\mathrm{EP}_{R . J .}$ and $\mathrm{CP}_{R . J .}$ indices can well depict the characters of the CP/EP type El Niño events. The major reason remains in the facts that both their new indices are still highly correlated to the traditional Niño-3 and Niño-4 indices ( 0.97 between Niño-3 index and $\mathrm{EP}_{R . J}$. index and 0.88 between Niño-4 index and $\mathrm{CP}_{R . J}$ index). As a matter of fact, one can almost get the identical $\mathrm{CP} / \mathrm{EP}$ indices to the $\mathrm{CP}_{R . J .} / \mathrm{EP}_{R . J .}$ indices by linearly fitting Niño-3 and Niño-4 indices directly. For example, one can get these two indices by Equ. (2):

$$
\left\{\begin{array}{l}
\mathrm{EP}_{R . J .} \approx 0.957 N_{3}-0.329 N_{4} \\
\mathrm{CP}_{R . J .} \approx 0.939 N_{4}-0.354 N_{3}
\end{array}\right.
$$



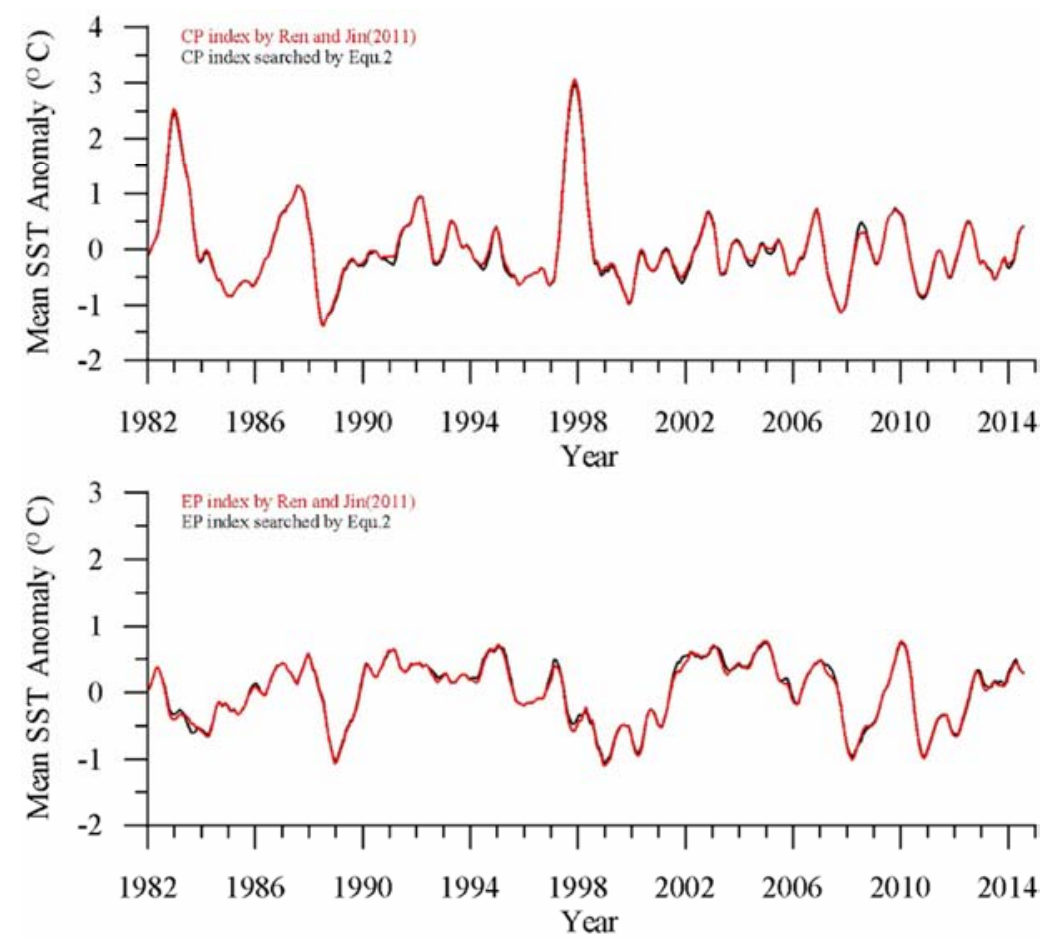

Figure 3. Comparison between the indices by Ren and Jin (2011, with alpha=2/5 in Equ. (1)) and the indices produced by Equ. (2).

Figure 3 shows the linear fittings in Equ. (2) (both correlations higher than 0.99), which suggests that the piecewise transformation in Equ. (1) by Ren and Jin (2011) is actually not the only way to achieve the $\mathrm{EP}_{\text {R.J. }} / \mathrm{CP}_{\text {R.J. }}$. indices. Figures 1, 2, 3 together show that the $\mathrm{EP}_{\text {R.J. }} / \mathrm{CP}_{\text {R.J. }}$. indices, in nature, can be acquired by searching for a minimum correlation in between through a linear fitting scheme like Equ. (1) or (2). The physical significance of the $\mathrm{EP}_{R . J .} / \mathrm{CP}_{R . J}$. indices by Ren and Jin (2011) alone is not very clear. However, it is easy to get Equ. (3) from Equ. (2):

$$
\mathrm{EP}_{R . J .}-\mathrm{CP}_{R . J .}=1.31 N_{3}-1.27 N_{4} \approx 1.3\left(N_{3}-N_{4}\right)
$$

Some previous studies used the differences between the Niño-3 and Niño-4 indices to track the El Niño features such as Kug et al. (2009), Yeh et al. (2009) and Kao and Yu (2009). Equ. (3) points out that Ren and Jin (2011) had amplified the differences by a factor of 1.3 (correlation between the $\mathrm{EP}_{R . J .}{ }^{-}$ $\mathrm{CP}_{R . J \text {. }}$ and Niño-3 - Niño-4 time series is higher than 0.99). It suggests that the Niño-3 and Niño-4 difference is a key point in many of previous studies concerning the El Niño flavors, including that by Ren and Jin (2011).

From Equ. (2), one can also easily have (correlation is almost 1):

$$
\mathrm{EP}_{R . J .}+\mathrm{CP}_{R . J .}=0.60 N_{3}+0.61 N_{4} \approx 0.6\left(N_{3}+N_{4}\right)
$$

Correlation between $\mathrm{EP}_{R . J .}+\mathrm{CP}_{R . J \text {. }}$ (also 0.6 $\left(N_{3}+N_{4}\right)$ ) and Niño-3.4 index is close to 0.99 (see Figure 4 ) and then one almost has ( $N_{3.4}$ denotes Niño-3.4 index):

$$
\mathrm{EP}_{\text {R.J. }}+\mathrm{CP}_{\text {R.J. }} \approx 0.6\left(N_{3}+N_{4}\right) \approx N_{3.4}
$$

Equ. (3) and Equ. (4) together can give Equ. (6) (both correlations higher than 0.99 ):

$$
\left\{\begin{array}{c}
\mathrm{EP}_{R . J .} \approx 0.3\left(N_{3}+N_{4}\right)+0.65\left(N_{3}-N_{4}\right) \approx 0.5 N_{3.4}+0.65\left(N_{3}-N_{4}\right) \\
\mathrm{CP}_{R . J} \approx 0.3\left(N_{3}+N_{4}\right)-0.65\left(N_{3}-N_{4}\right) \approx 0.5 N_{3.4}-0.65\left(N_{3}-N_{4}\right)
\end{array}\right.
$$

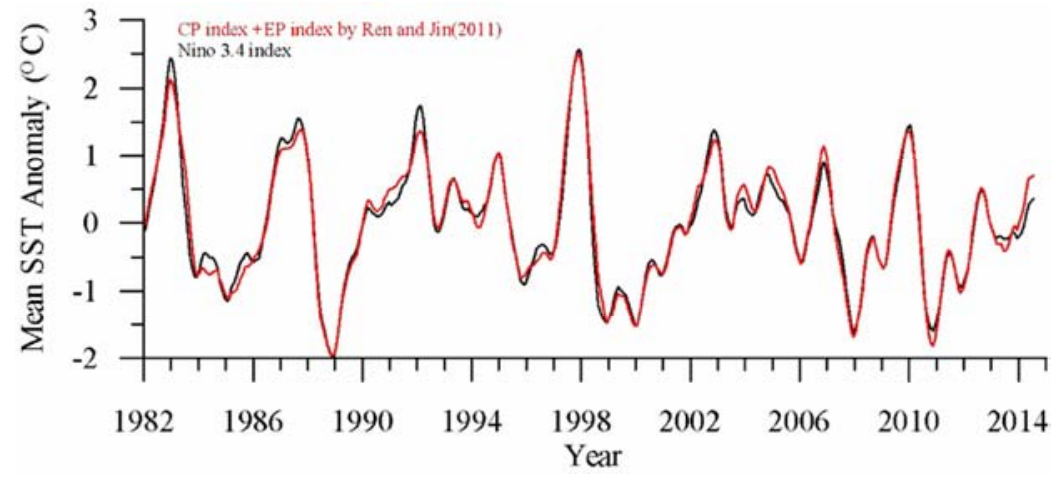

Figure 4. Comparison between the CP+EP indices by Ren and Jin (2011) and the Niño 3.4 index. 
Equ. (3), Equ. (5) and Equ. (6) together give the nature and the origin of the $\mathrm{EP}_{R . J}$ and $\mathrm{CP}_{R . J}$ indices quantitatively with very high confidence level. The sum of the $\mathrm{EP}_{R . J}$ and $\mathrm{CP}_{R . J}$. indices is equivalent to the Niño 3.4 index and the difference between the $\mathrm{EP}_{R . J \text {. }}$ and $\mathrm{CP}_{\text {R.J. }}$ is an amplified version of the Niño-3 and Niño-4 difference.

This study argues that the low correlation between the $\mathrm{EP}_{R, J}$ and $\mathrm{CP}_{R, J}$ indices results from the low correlation between the right sides of Equ. (6) (simultaneous correlation in between is near 0.14).

The simultaneous correlation between the TNI and Niño-3.4 is about -0.25 (Trenberth and Stepaniak, 2001) and that between the $\mathrm{EP}_{R . J .}$ and $\mathrm{CP}_{R . J}$ is about 0.14 . These two values are indicative of key features associated with El Niño events. In detail, the correlation $(-0.25)$ between the TNI and Niño-3.4 suggests that the SSTA gradient along the Pacific equator is nearly independent of the mean SSTA of the Pacific equator and the correlation $(0.14)$ between the $\mathrm{EP}_{R . J \text {. and }} \mathrm{CP}_{R . J \text {. }}$ suggests that the $\mathrm{CP}$ and EP El Niño events are almost independent between them. In physics, the independence of the $\mathrm{CP}$ and EP El Niño events results in the independence of the TNI/Niño-3.4 indices but the independence of the TNI/Niño-3.4 indices could not necessarily result in a complete independence of CP and EP El Niño events. For example, the co-existence of the CP and EP El Niño events but with independent strength can also cause the independence of the TNI/ Niño-3.4 indices. The low correlation between the $\mathrm{EP}_{R . J}$. and $\mathrm{CP}_{R . J}$. indices indicates that the $\mathrm{CP}$ and $\mathrm{EP}$ type $\mathrm{El}$ Niño events are not coherent. Therefore, further investigations are required on the independent features among El Niño events.

\subsection{Experimental Definitions of the Spatial Coverage for the New EP/CP Indices}

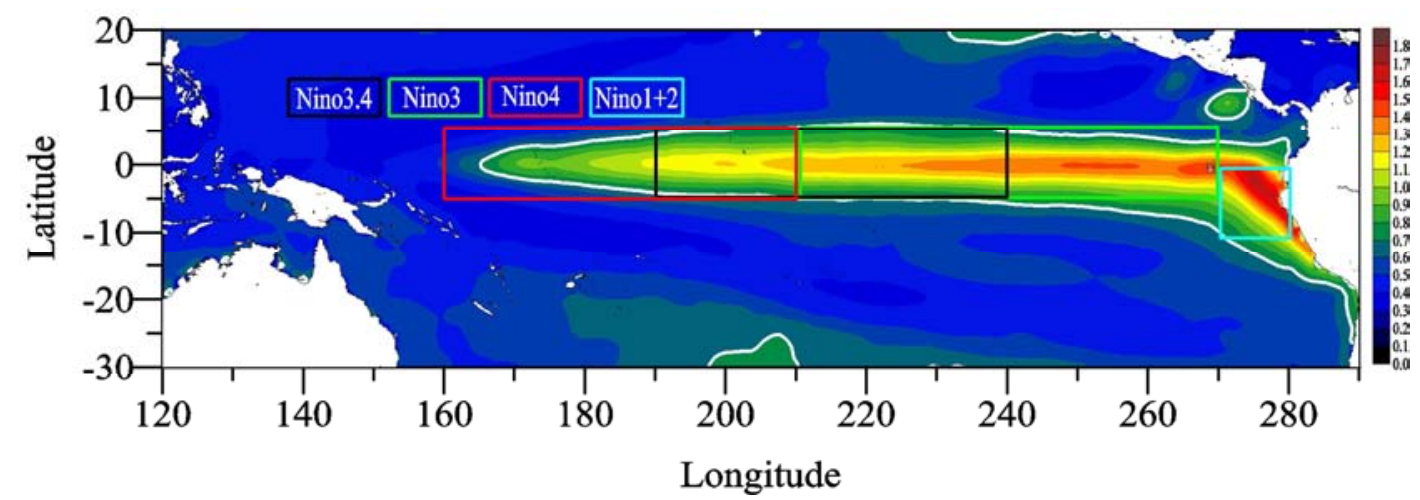

Figure 5. Coverage of traditional Niño regions and contour line (white line, $0.7^{\circ} \mathrm{C}$ ) of the standard deviation of the SST anomalies along the Pacific equatorial regions (1981-2014). It should be noted that, a $0^{\circ}-360^{\circ} \mathrm{E}$ system instead of a $180^{\circ} \mathrm{W}-0^{\circ}-180^{\circ} \mathrm{E}$ system for all the maps in this paper is used for a continuity consideration.

Previous studies show that there are great differences in the SSTA distributions between the CP and EP types events along the Pacific Equators in the El Niño regimes (Kao and Yu, 2009; Yeh et al., 2009; Yu et al., 2011; Fang et al., 2013; Ren et al., 2013; Takahashi and Dewitte, 2015) but there are currently no CP or EP indices established based on their natural spatial distribution of the SSTA features yet. In other words, no pair of truly orthogonal indices is able to provide independent features associated with El Niño events. Here, this study defines new $\mathrm{CP}$ and EP regions, arguing that the lack of truly orthogonal indices is because that, up to now, not-so-naturally defined rectangular traditional Niño regions have always been investigated.

The standard deviation distribution of the equatorial SSTA is shown in Figure 5 and the patterns are very similar to that of Fang et al. (2013) and that of Deser et al. (2010). As can be seen, the eastern Pacific equator SSTA has great non-seasonal variability. The traditional Niño region coverage (Trenberth, 1997) and the UNR (Fang et al., 2013) are shown together in Figure 5. It should be noted that the standard deviation distribution pattern of the SSTA of the equatorial Pacific Ocean is quite stable as can be seen from the comparisons with previous results (Deser et al., 2010; Fang et al., 2013).

Fang et al. (2013) showed that all the traditional Niño index time series (such as the Niño-1+2, the Niño-3, the Niño-4, the Niño-3.4 and the TNI) can be well described by the linear combination of the mean SST anomaly and the ZTC anomaly time series of the UNR as Equ. (7) below:

Niño Index $(t)=$ Coeff $1+\operatorname{Coeff} 2 \times$ the mean SST anomaly $(t)+$ Coeff $3 \times$ the ZTC anomaly $(t)$

where Coeff1, Coeff 2 and Coeff3 are the regression coefficients for each traditional Niño Index. Although Takahashi et al. (2011) showed that the standard ENSO indices could be reproduced with high fidelity through a linear combination of the first two leading principal components (PCs) of tropical Pacific SSTs, the method by Fang et al. (2013) to reconstruct the traditional ENSO indices is much simpler with equivalent fidelity. The first 2 PCs of Takahashi et al. (2011) only accounts for $82 \%$ of the ENSO signals.

The ZTC of the UNR is simply determined by Equ. (8) as Fang (2006) and Fang et al. (2013): 


$$
Z T C=\sum_{i}\left(S S T_{i} \cdot \text { Longitude }_{i}\right) / \sum_{i} S S T_{i}
$$

where $S S T_{i}$ stands for the grid temperature within the UNR. The ZTC anomaly time series are calculated by removing the monthly climatology.
This study further tries to linearly regress the SSTA monthly time series (spanning from 1982 to 2014) of each grid along the Equatorial Pacific regions from the same two time series of the mean SST anomaly and the ZTC anomaly of the UNR, as outlined by Equ. (9):

SST anomaly $($ lon, lat, $t)=$ Coeff1(lon, lat $)+\operatorname{Coeff} 2($ lon, lat $) \times$ the mean SST anomaly $(t)+$ Coeff3(lon, lat $) \times$ the ZTC anomaly $(t)(9)$

For each grid location (lon, lat), there is a specific set of Coeff1 (lon, lat), Coeff2 (lon, lat) and Coeff3 (lon, lat).

The correlation information between the time series of the SSTA of each grid within the UNR and its regression outputs from Equ.9 can be found in Figure 6 and Figure 7. The distribution of the regression correlation coefficients are shown in Figure 6. The regression coefficient distributions of Coeff1, Coeff 2 and Coeff3 in Equ. (9) are shown in Figures 7a, $\mathrm{b}$, and c respectively. As expected, Figure 6 shows that the SSTA time series of each grid within the UNR can be well described by the simple linear fittings of Equ. (9).

The Coeff1 (lon, lat) is the constant component of the grid SSTA. The Coeff2(lon, lat) shows how much the grid SSTA changes resulted by a $1^{\circ} \mathrm{C}$ change of the mean SSTA of the UNR. The Coeff3 (lon, lat) shows how much the grid SSTA changes resulted by a $1^{\circ}$ change (in longitude) of the ZTC anomaly of the UNR. The Coeff2 (lon, lat) and Coeff3 (lon, lat) reflect the sensitivity of the grid SSTA to the changes of the mean SSTA and the ZTC anomaly of the UNR, respectively. Figure 7a suggests that Coeff1 (lon, lat) is somewhat small and can be neglected. Figure 7b suggests that nearly all the SSTA time series within the UNR are positively correlated to the mean SSTA of the UNR. Figure 7c indicates that the SSTA time series of different grid within the UNR are differently correlated with the ZTC anomaly of the UNR. Furthermore, the maximum values of Coeff2 (lon, lat) are mainly within the Niño-3.4 region where the grid SSTA is most sensitive to the mean SSTA change of the UNR. It's also observed that the maximum values of Coeff3 (lon, lat) are mainly within the Niño-1+2 region where the grid SSTA is most sensitive (positively correlated) to the ZTC anomaly change of the UNR. The minimum values of Coeff3 (lon, lat) are mainly within the Niño-4 region where the grid SSTA is most sensitive (negatively correlated) to the ZTC anomaly change of the UNR. This feature is consistent with the TNI/Niño-3.4 definition adopted by Trenberth and Stepaniak (2001) to track the El Niño flavors. In Figure 7, the simply acquired distribution patterns of Coeff2(lon, lat) and Coeff3(lon, lat) are very similar to those of the EOF1 and EOF2 modes of Takahashi et al. (2011) and Cai et al. (2015), and these features point out that the methodology used here is versatile and consistent with previous results.

Because the coeff3(lon, lat) in Figure 7c shows the sensitivities of the grid temperature anomaly to the ZTC anomaly of the UNR and the ZTC anomaly reflects the surface thermal distribution changes along the Pacific Equator (Fang et al., 2013), the coeff3(lon, lat) distribution patterns could provide guidelines for the new definitions of the CP or EP regions. In Figure 8, the SSTA time series of each grid along the yellow contour line (on which the Coeff3 equals zero in Figure7c) depend only on the mean SSTA time series of the UNR, and are almost independent of the ZTC anomaly time series of the UNR. The yellow line "naturally" divides the UNR into two parts: the central Niño region and the eastern Niño region, as denoted as the $\mathrm{CP}$ and the EP region in Figure 8 respectively. In the study by Peng et al. (2011), the EP El Niño events (the CP El Niño events) are defined as El Niño with anomalous warm water originating first from the east (the west) of $120^{\circ} \mathrm{W}\left(240^{\circ}\right.$ in Figure 8), just near which the yellow lines are located.

Takahashi et al. (2011) and Cai et al. (2015) suggested that the central Pacific El Nino might not be a distinct mode but rather is a part of ENSO asymmetry. However, their conclusions currently disagree with most of the previous studies dealing with the $\mathrm{CP} / \mathrm{EP}$ classification.

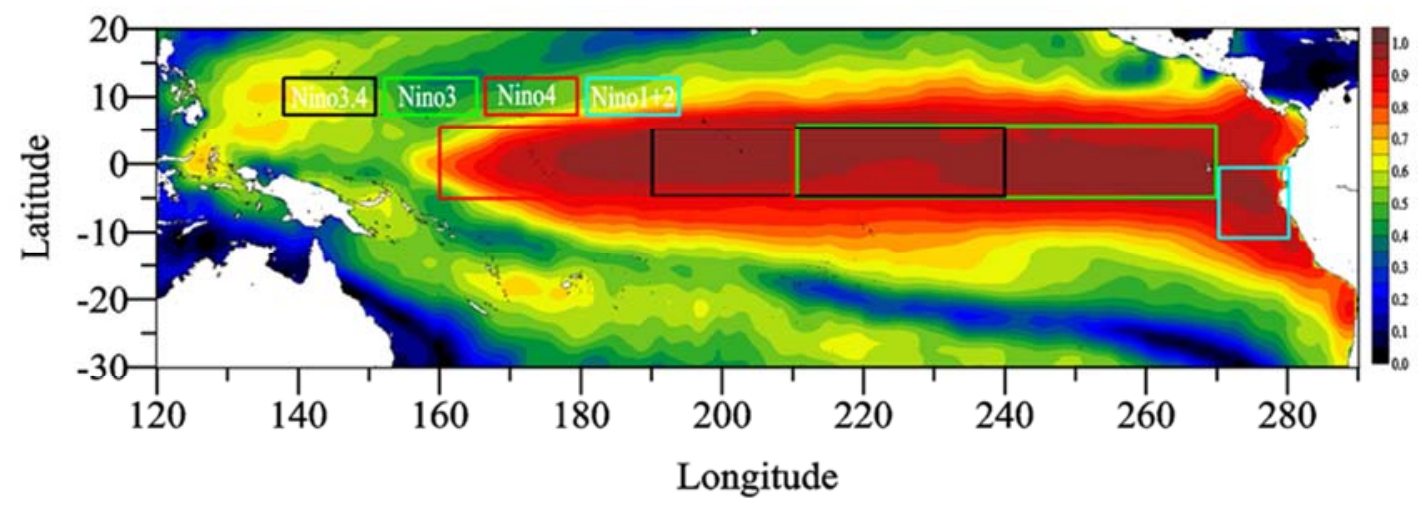

Figure 6. Simultaneous correlation coefficient distribution (absolute values) between the grid SSTA time series and the linear fitting output by Equ.9. This image shows that almost all the SSTA time series within the UNR can be well reconstructed by the linear combination of the SSTA and the ZTC anomaly of the UNR. 


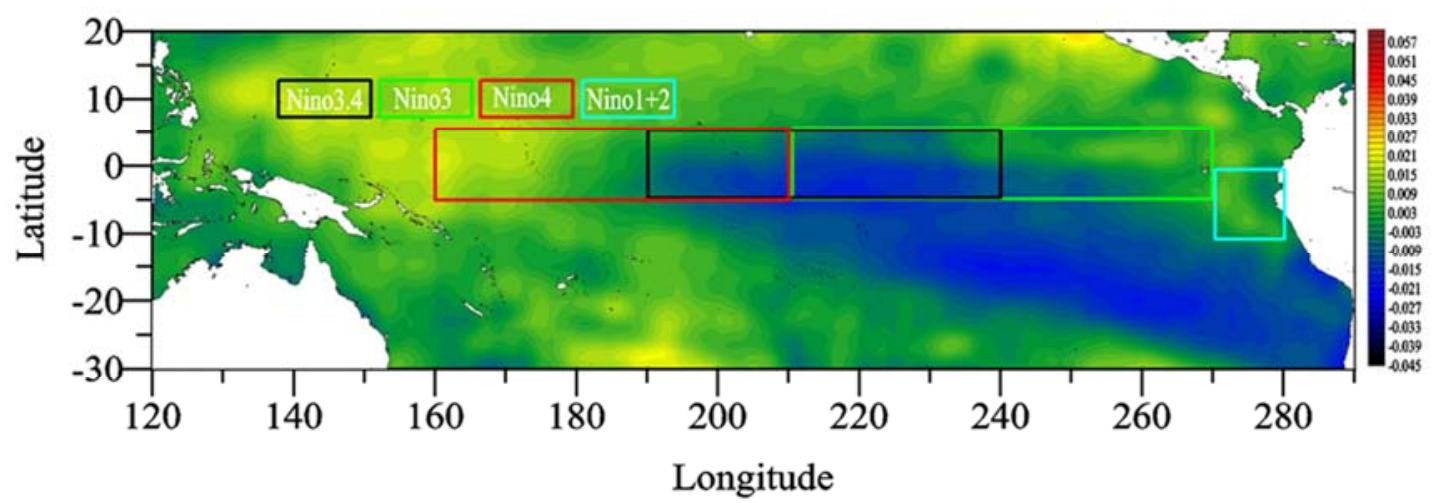

(a)

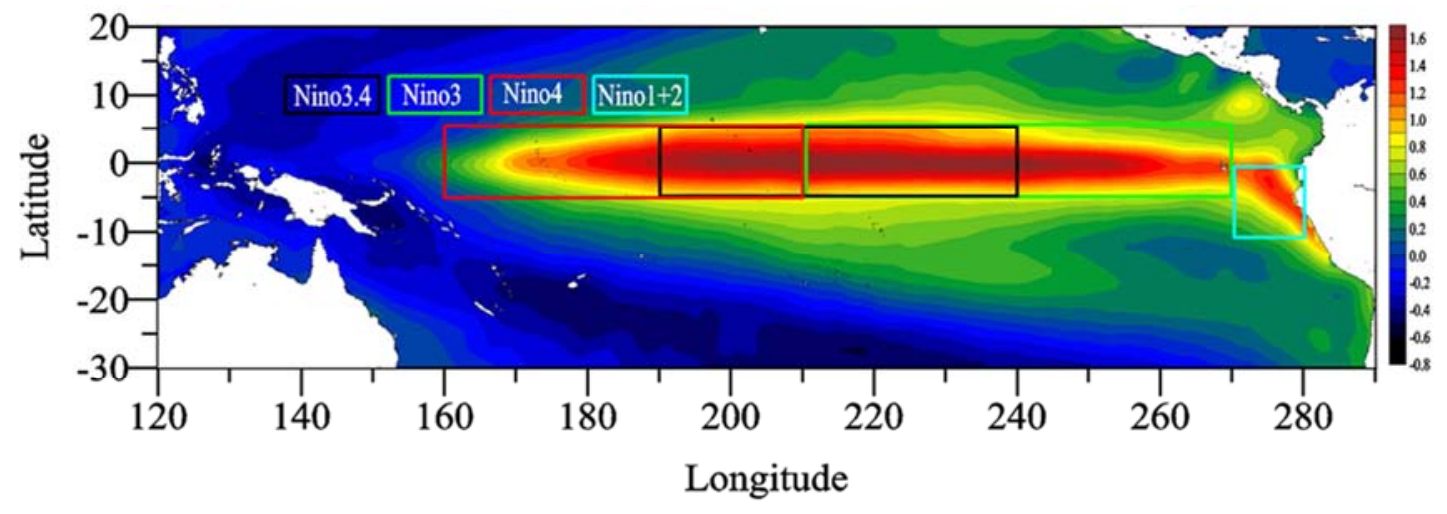

(b)

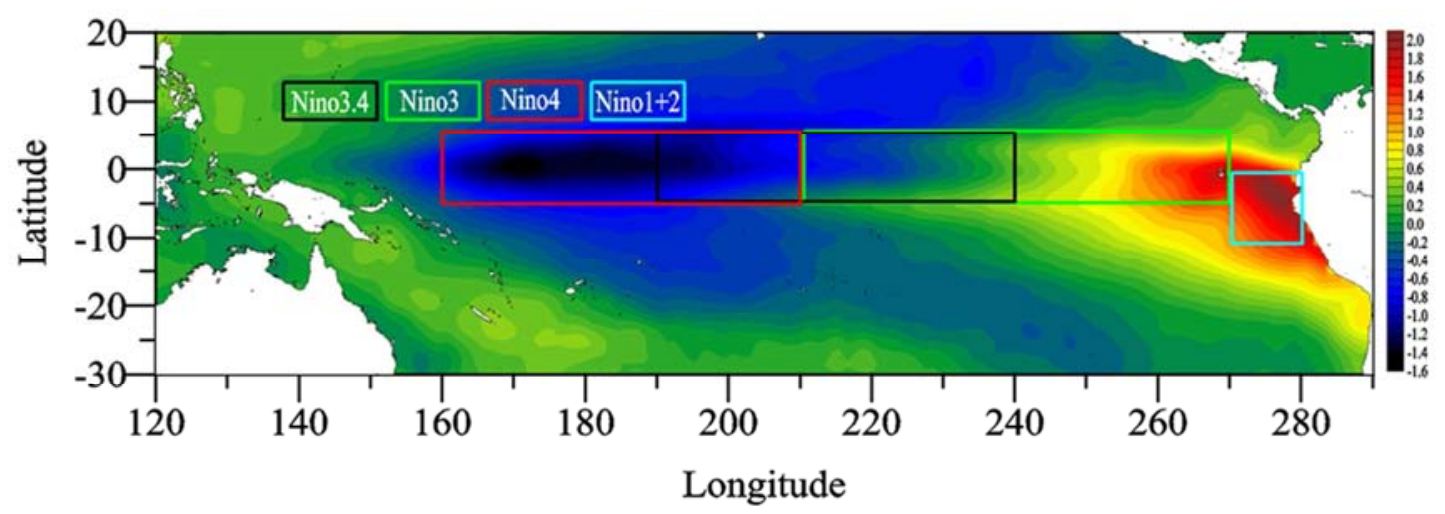

(c)

Figure 7. Linear fitting coefficient distribution in Equ.9 of the grid SSTA along the Pacific equator. (a) is for coeff1, (b) is for coeff2 and (c) is for coeff3.

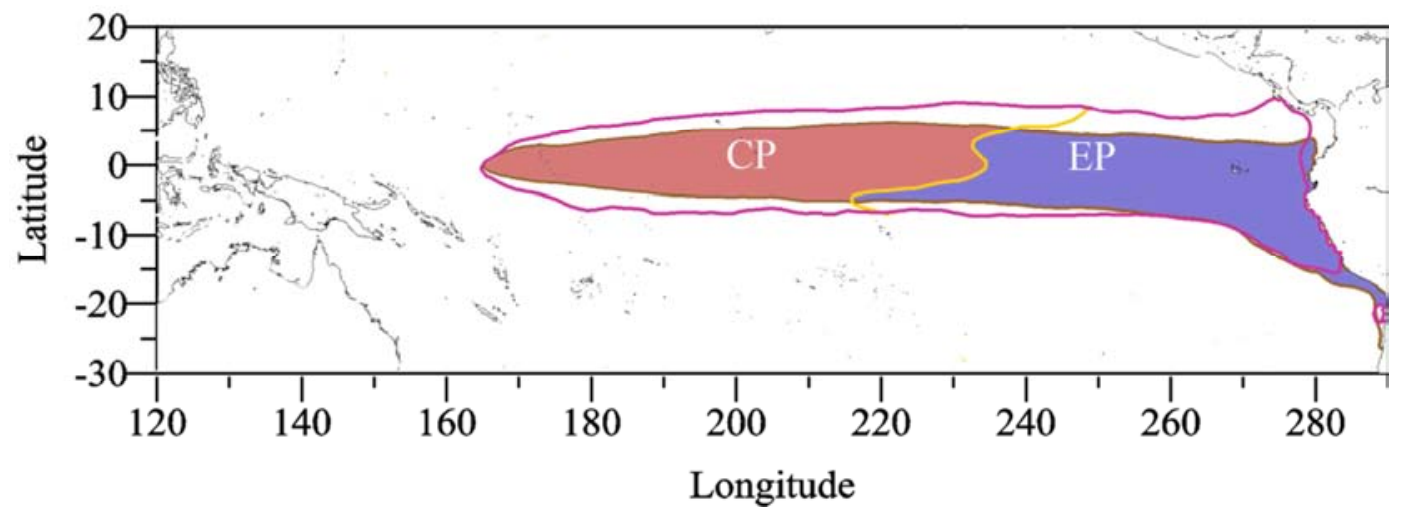

Figure 8. Experimental CP Niño region (pink areas) and EP Niño region (blue areas) definition. The brown line is the $0.7^{\circ} \mathrm{C}$ contour line outline the UNR as Fang et. al, 2013. The yellow line is the 0.0 Coeff3 contour line in Figure7c. The purple line is the 0.85 correlation contour line in Figure 6. 


\section{Results and Discussion}

\subsection{Comparison Between the New EP/CP Indices and the $\mathrm{EP}_{R . J}$ and $\boldsymbol{C P}_{R . J}$ Indices}

Figure 9a shows the mean SSTA time series of the new CP and EP regions as the new $\mathrm{CP}$ and EP indices by this study. In Figure 9, the simultaneous correlation between the new CP index and the $\mathrm{CP}_{R . J \text {. }}$ index is 0.98 and that between the new

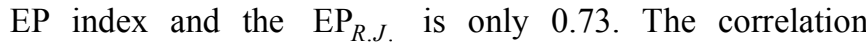
between the new CP and new EP indices by this study is 0.73 and the correlation between the $\mathrm{CP}_{R . J}$. and $\mathrm{EP}_{R . J}$. indices is only 0.14. Figure 9a suggests that the new CP and EP Niño indices are not independent of each other, and this is a result somewhat different from those presented by Ren and Jin (2011).

The low correlation between the $\mathrm{CP}_{R . J}$. and $\mathrm{EP}_{R . J \text {. }}$ indicates that the CP and EP types of El Niño events are almost independent to each other. This brings some controversial understandings. For example, what are the physical backgrounds of the $\mathrm{CP}_{R . J}$. and $\mathrm{EP}_{R . J \text {. }}$ indices of their study? Do they reflect the local temperature anomalies? It is interesting that, the $\mathrm{CP}$ or EP type El Niño features were captured by the SSTA distribution along the Pacific equator, but the $\mathrm{CP}_{\text {R.J. }}$ and $\mathrm{EP}_{\text {R.J. }}$ indices were unable to show the local mean SSTA features quite well. For example, the five important El Niño events showed in Figure 10 all indicate that the two types El Niño events often co-exist, at least during the early stages. Some recent studies have focused on the co-existence of the two types of El Niño events (Bejarano and Jin, 2008; Yeh et al., 2009; Kug et al., 2010; Yu and Kim, 2013; Ren et al., 2013) and there are some inner connections between these two types of El Niño events (Zheng et al., 2014) However, in Figure 9b it's noted that some presumed co-existence of the two types of El Niño events, described by the $\mathrm{CP}_{R . J}$. and $\mathrm{EP}_{\text {R.J. }}$. indices, disappears, and that these two indices are unable to correctly capture the features of El Niño evolutions. For example, the $\mathrm{CP}$ region continuing warming after Jun.1982 revealed by Figure 10 was missing in Figure $9 \mathrm{~b}$; the transition from an EP/CP coexistence El Niño to a CP El Niño around 2010 is also missing in Figure $9 b$. Actually some of the $\mathrm{CP}$ or EP classifications contradict previous results. For example, the 1986-1987 El Niño was classified as a CP type of El Niño by Kao and Yu (2009), but Figure $9 \mathrm{~b}$ suggests that the $\mathrm{EP}_{\text {R.J. }}$. index was higher than the $\mathrm{CP}_{R . J}$. index during that period. Xiang et al. (2012) and $\mathrm{Yu}$ and Kim (2013) regarded the 2009-2010 event as a CP type of El Niño (as this study also suggests), but the $\mathrm{CP}_{R . J}$. and $\mathrm{EP}_{\text {R.J. }}$ indices gave comparable magnitudes. Recent analysis by Paek et. al. (2017) shows that the 2015-16 El Niño was a mixture of the EP and CP types and their CP and EP indices have comparable magnitudes. The $\mathrm{CP}_{\text {R.J. }}$ and $\mathrm{EP}_{\text {R.J. }}$ indices seems to fail to capture this feature during the 2015-16 event.

New indices by this study in Figure 9a agree quite well with previous findings. As a whole, one can find that in the recent more than 30years, the CP type of El Niño events have happened much more frequently than the EP type El Niño events, a feature consistent with previous studies (Yeh et al., 2009; McPhaden et al., 2011; Xiang et al., 2012). The Jan.-Jun.1982 period was classified as CP type and the late stage of 1982-1983 El Niño was classified as EP type by Kao and Yu (2009). This transition can be seen clearly from Figure 9a. Before Jun. 1982, the CP index was higher than the EP index and after Jun. 1982, the relationship between these indices appears reversed. Kao and Yu (2009) also pointed out that a cold CP stage began after Apr. 1983, a feature in agreement with results displayed in Figure 9a. Nevertheless, Figure $9 \mathrm{~b}$ shows that the cold CP came too early. One can also find that the cold CP of 1997-1998 by Ren and Jin (2011) in Figure $9 \mathrm{~b}$ came too early according to the analysis by Kao and $\mathrm{Yu}$ (2009). The two EP/CP mixed events indicated by $\mathrm{Yu}$ and Kim (2013), i.e., the 1986-1987 and the 2006-2007 events, were clearly shown by Figure 9a, with comparable CP and EP indices during those periods. The comparable CP and EP indices are also found for the 2015-16 event in Figure 9a, similar to the result by Paek et. al. (2017).

A detailed comparison between the classification results of the CP and EP type El Niño events by Yu and Kim (2013) and by this study shows the two results agree perfectly with each other and hints that the CP and EP Niño region definition by this study is one of the proper choices. Those El Niño events (1986-1987; 2006-2007; 2015-2016) classified as "Mix" by $\mathrm{Yu}$ and Kim (2013) or Paek et. al. (2017) have the similar magnitudes of CP and EP indices; those El Niño events (1982-1983; 1997-1998) classified as "EP" by Yu and Kim (2013) have greater EP indices than CP indices and almost all the other El Niño events classified as "CP" by $\mathrm{Yu}$ and Kim (2013) have greater CP indices than EP indices. The indices by Ren and Jin (2011) could not capture typical "Mix" features of the El Niño events.

Banholzer and Donner (2014) focused on the inconsistences emerging when El Niño types are classified. Currently, whether and how the EP and CP types of El Niño events co-exist are hot and unresolved issues. There are even some controversial conclusions of the El Niño classification. For example, Kao and Yu (2009) and Peng et al. (2011) classified the 1986-87 event as the CP type El Niño, but according to the studies by Xiang et al. (2012) and Zheng et al. (2014), the 1986-87 event was treated as EP type El Niño. This study (see Figure 9a) suggests that the CP type and the EP type indices are of comparable magnitudes, which indicate that both the CP type and EP type co-existed, which is also clearly shown by Figure 10. Statistics in a detailed El Niño classification by $\mathrm{Yu}$ and $\mathrm{Kim}$ (2013) showed that, from 1867 to 2010 , there were $15 \mathrm{EP} / \mathrm{CP}$ mixed events out of total 39 events during that period; and that there were only 13 El Niño events out of the total 39 events could be agreed to be of the same type with different methods. These facts suggest again that the very low correlation between the CP and EP indices should be reconsidered. Actually, Figure 9a and Figure 10 show that the CP and EP types of El Niño events happened with a relatively high possibility of co-occurrence which causes a high correlation between the $\mathrm{CP}$ and EP indices. 
The new CP and EP indices formulated in this study give a more detailed description on the El Niño events. Although the correlation between the new $\mathrm{CP}$ and EP indices by this study is higher than that of Ren and Jin (2011), it could result from the frequent co-existence (sometimes with leads and lags) of these two types of El Niño events (Yu and Kim, 2013; Ren et al.,
2013). The low correlation between these two types of El Niño indices is not necessarily physical as suggested by Ren and Jin (2011). However, it is very difficult to ascertain the total independence between these two types of El Niño events and further studies are required on this topic (Yu and Kim, 2013; Zheng et al., 2014; Capotondi et al., 2014).

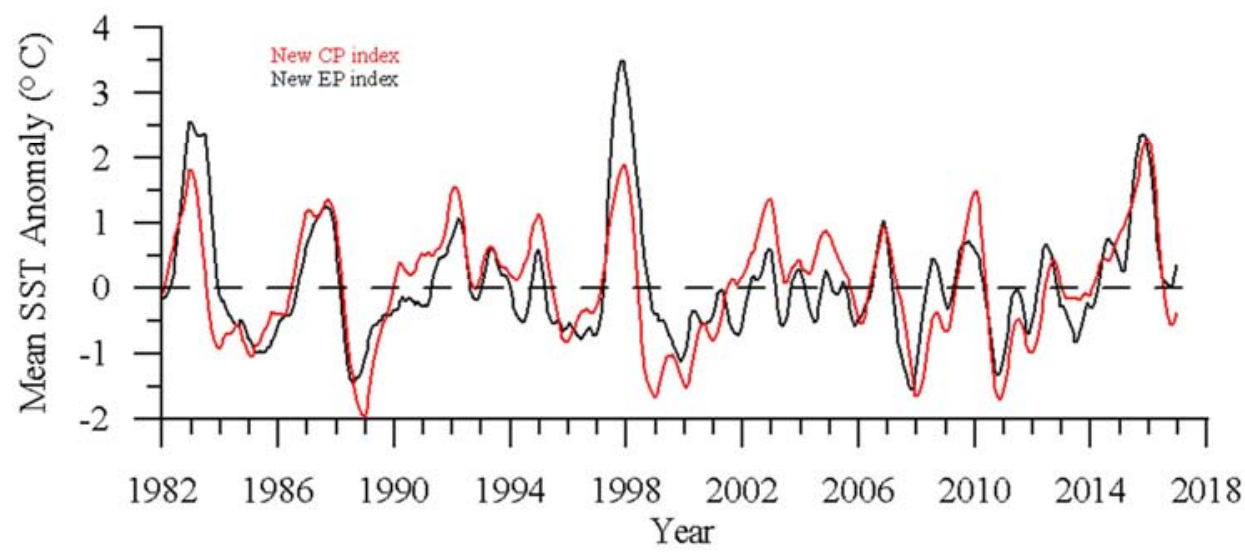

(a)

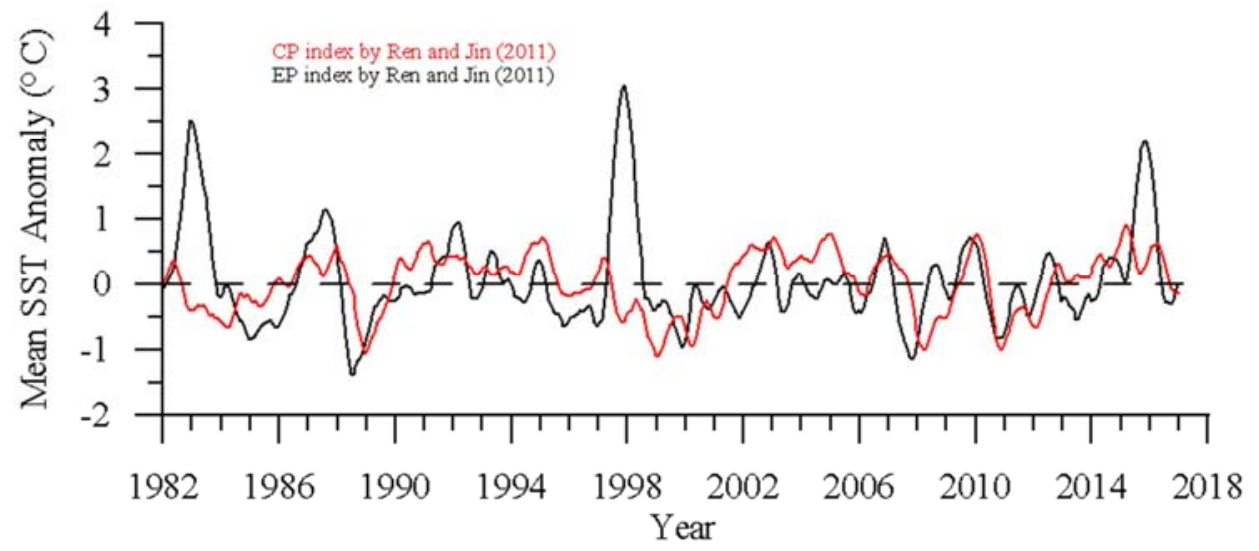

(b)

Figure 9. CP and EP indices. (a) Defined by this study and (b) defined by Ren and Jin (2011). It should be noted that the data time range has been extended a bit to the year of 2017 to further check the validity of the new CP and EP region definitions.
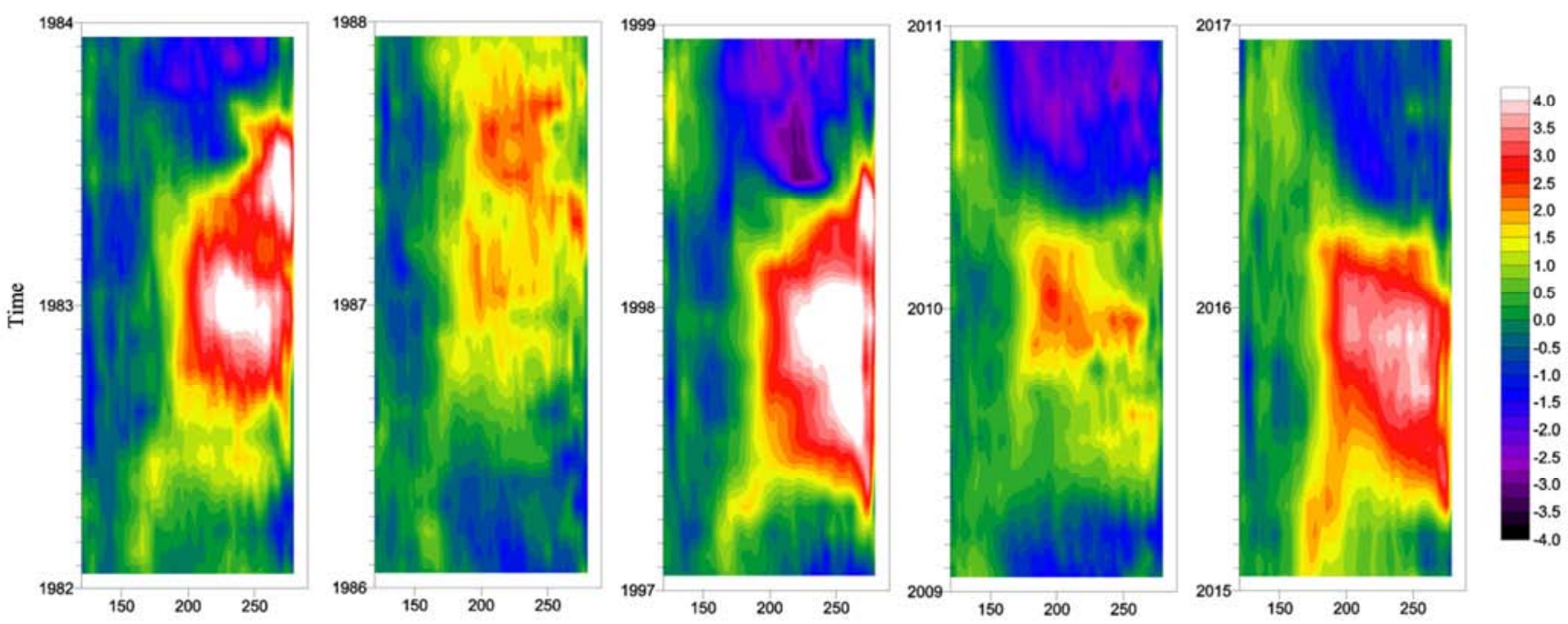

Longitudes along the Pacific equator (Deg.)

Figure 10. Five El Niño events' evolution (SSTA) history in recent years in Longitude-Time plots along the Pacific equator. 


\subsection{Important Features of the New EP/CP Indices}

Figure 11 shows the correlation between the TNI index and the EP/CP index difference. It's should be noted that the difference between the new CP and EP indices by this study is much more correlated to the TNI index than the difference between the $\mathrm{EP}_{\text {R.J. }}$ and $\mathrm{CP}_{\text {R.J. }}$ indices. Figure 11 also shows that difference between the $\mathrm{EP}_{R . J}$. and $\mathrm{CP}_{R . J \text {. }}$ is unable to clearly depict the temperature gradient along the Pacific equator. On the contrary, the difference between the new CP and EP indices by this study is highly correlated with the TNI index, reflecting quite well the temperature gradient along the Pacific equator and thus bearing more physical significance than the $\mathrm{EP}_{\text {R.J. }}$ and $\mathrm{CP}_{\text {R.J. }}$ indices.

In Figure 12, the black line shows the lead-lag correlation between the new EP/CP difference (EP index minus CP index) and the mean SSTA of the UNR (with a 0.0 simultaneous correlation). The red line shows the correlation between the TNI index and the Niño 3.4 (with a -0.25 simultaneous correlation). The blue line shows the correlation between the

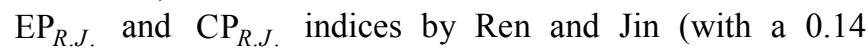
simultaneous correlation). Figure 12 suggests that the difference between the new CP and EP indices and the mean SSTA of the UNR are truly independent of each other. This finding is consistent with that presented by Trenberth and Stepaniak (2001) concerning the relationship between the Niño 3.4 and TNI indices. The author regards the relation between the mean SSTA of the UNR and the new CP and EP index difference as an improved version of that between the Niño 3.4 index and TNI index group. This study confirms that the mean SSTA of the Niño regions and the SSTA gradient across the Pacific equator are truly independent measurements for the El Niño features, which hints that even if the strength of the El Niño event can be predicted, the SSTA distribution feature prediction across the equatorial Pacific will be a great challenge. Recently Guckenheimer et. al. (2017) suggests that the timing of strong El Ni no events on decadal time scales is unpredictable because the weak seasonal forcing or noise in the "recharge oscillator" model of ENSO can induce irregular switching between an oscillatory state that has strong El Ni no events and a chaotic state that lacks strong events. Their conclusions agree well with the results of this study.

The variation of the CP and EP index differences is dynamically induced by the different warming rates of the EP and $\mathrm{CP}$ region mean SSTA. Figure 13a shows the CP index, the EP index and the warming rate difference between the $\mathrm{CP}$ indices and the EP indices. The CP/EP classification results by Yu and Kim (2013) are also shown in Figure 13a. Figure 13b shows the continuous wavelet spectrum(in magnitudes) patterns of the warming rate difference between the CP and EP regions, which, in physics, indicates that the $\mathrm{CP}$ warming rate and EP warming rate are always competing semi-periodically. It's noted that, the warming rate difference between the $\mathrm{CP}$ and EP regions gives rise to an unstable ENSO-like oscillation (Figure 13b). Figure 13 shows that, an EP warming faster (or cooling slower) event is often followed by a $\mathrm{CP}$ warming faster (or cooling slower) event, and vice versa, although in only a few cases, the CP or EP warming rate differences were very weak. Figure 13 shows clearly that within the Niño regions, there also exists an internal see-saw like oscillation. As the CP and EP indices are the result of the temporal accumulation of the $\mathrm{CP}$ and $\mathrm{EP}$ warming rate respectively, the $\mathrm{CP} / \mathrm{EP}$ warming rate competition in these two regions, as an intrinsic oscillation mode, has important influences on the final stages of the Niño events. Figure 13 also suggests that although the $\mathrm{CP}$ warming and the EP warming may have different driving forcings (Capotondi et. al, 2014), these forcings certainly have interactions. This feature suggests that the CP and EP El Niño events should not be isolated.

It can be found in Figure 13a that, before the red line (CP index) rises up to cross the zero line, such as around Feb. 1982, Jun. 1986, Dec. 1989, Oct. 1992, Jun. 2001, May 2006, Apr. 2009, May 2012, Feb. 2014, the CP warming rates were higher than EP warming rates. Only around Feb.1997 when the CP line was rising up across the zero line, the $\mathrm{CP}$ warming rate was lower than EP warming rate. However, even for the 1997-98 case, there was also a short period during which the $\mathrm{CP}$ warming rate was higher than EP warming rate (as also can be seen in Figure 10). It shows that most of the CP warming cases (transitioning from negative SSTA to positive SSTA) were originated from its own CP regions. Another interesting point is that, in most cases (before 2007 and after 2014), when the black lines (EP index) transitioned from negative SSTA to positive SSTA, all the red lines (CP index) were already (or almost simultaneously) positive. There were only two exceptional cases: Apr. 2008 and Feb. 2012 (both of which were very weak EP warm events). This feature leads to the implication that most of the El Niño events began with a high $\mathrm{CP}$ warming rate, although sometimes the $\mathrm{CP}$ warming was very weak. It is noted that, in Figure 13a (and in Figure 9a), when the El Niño events happen, most of the CP peaks happen around the end of the calendar year (with only a few exceptions). For those strong ENSO events (1982-1983, 1997-1998, 2015-2016), the EP peaks arose no later than the CP peaks and the EP peak magnitudes were stronger than the $\mathrm{CP}$ peak magnitudes. For other weaker ENSO events, CP peaks arose no later than EP peaks and the CP peak magnitudes were stronger than the EP peak magnitudes (only the 2010 event was an exception). This study suggests that the temporal phases of the $\mathrm{CP} / \mathrm{EP}$ events are highly and mechanically correlated, although further investigations are required to better ascertain this relationship.

The CP warming events (whose warming rate is higher than that of the EP warming) happened during different seasons and last for different months. For example, the 1982-83 CP warming case began in the early 1982 and last for about 3 months, but the 1986-87 CP warming began in the end of the year and last for about 7 months. This feature suggests that the differences between the $\mathrm{CP} / \mathrm{EP}$ warming rates largely contribute to the El Niño characteristics. As for the two strong El Niño events, i.e., the 1982-1983 and 1997-1998 cases (Figure 13), both events showed larger EP index magnitudes than those associated with the CP index. This study also 
suggests that these two events both have two EP warming rate peaks within the EP warm episodes. These peaks agree with those displayed in Figure 10, in which there were twice of the maximum cores of the SSTA in both events (it should be noted that the time when the maximum SSTA occurred was not the time when the EP and CP warming rate difference peak occurred). The similarity between results presented in Figure 10 and Figure 13 also suggests that the $\mathrm{CP}$ and EP region definition by this study is physical and thus reasonable.
Analysis above suggests that the new CP and EP index differences are truly independent of the mean SSTA of the UNR, quantitatively confirming and improving the relationship between the traditional group indices of TNI and Niño-3.4. This study suggests that the fundamental independent factors of the El Niño events are the SSTA gradient along the Pacific equator and the mean SSTA within the Niño regions, not the CP and EP indices.

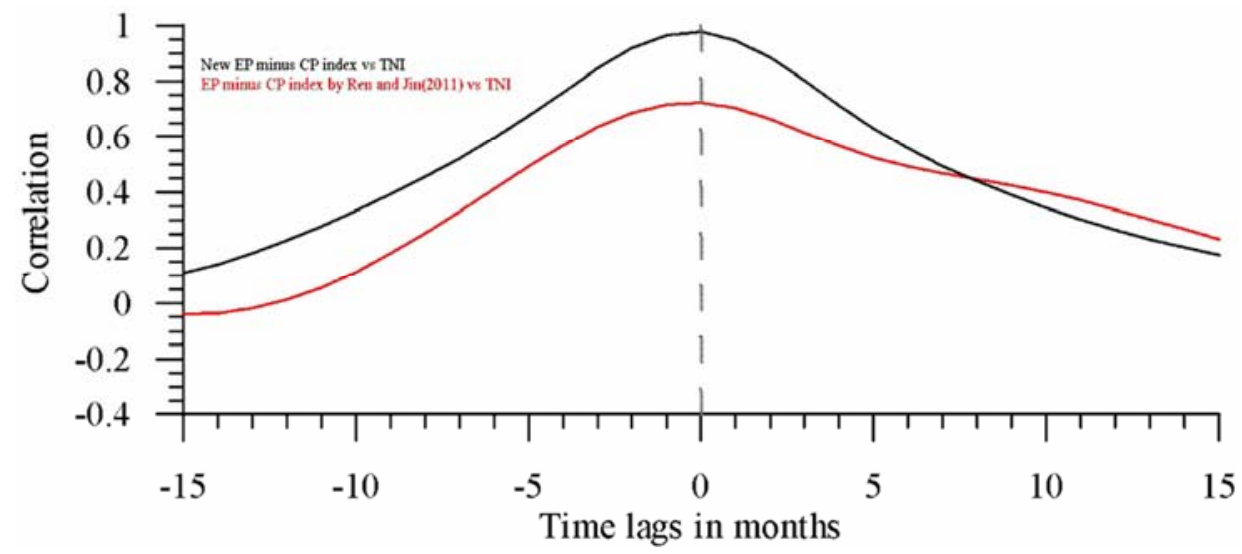

Figure 11. Black line: correlation between the new EP-CP index difference by this study and the TNI index (with a simultaneous correlation higher than 0.98) and Red line: correlation between the EP index minus CP index of Ren and Jin (2011) and the TNI index (with a simultaneous correlation of 0.72). This plots shows that the newly defined CP and EP indices' difference by this study is highly related to the TNI index.

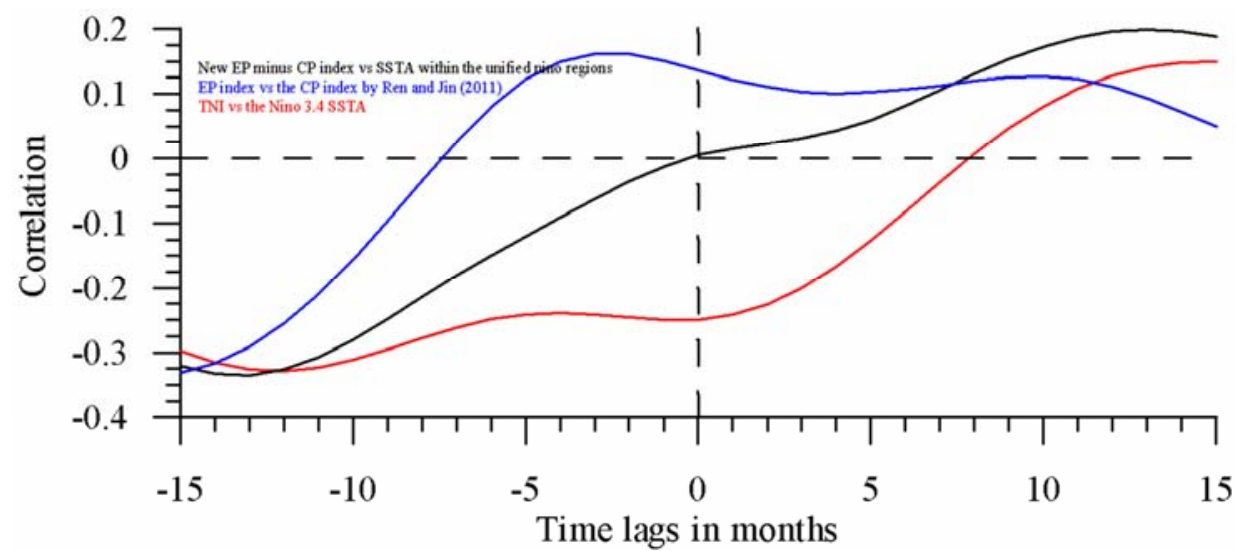

Figure 12. Black line: correlation between the new EP index minus CP index and the SSTA index of the UNR (with a simultaneous correlation of nearly zero). Red line: correlation between the TNI index and the Niño 3.4 (with a simultaneous correlation of -0.25). Blue line: correlation between the CP index and the EP index by Ren and Jin (with a simultaneous correlation of 0.14 ).

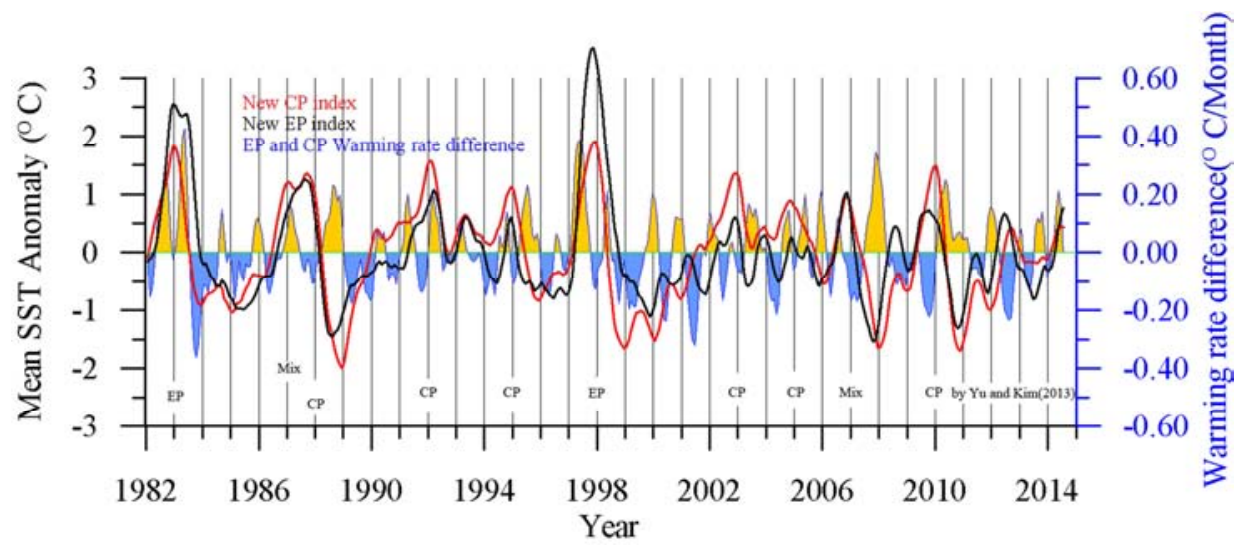




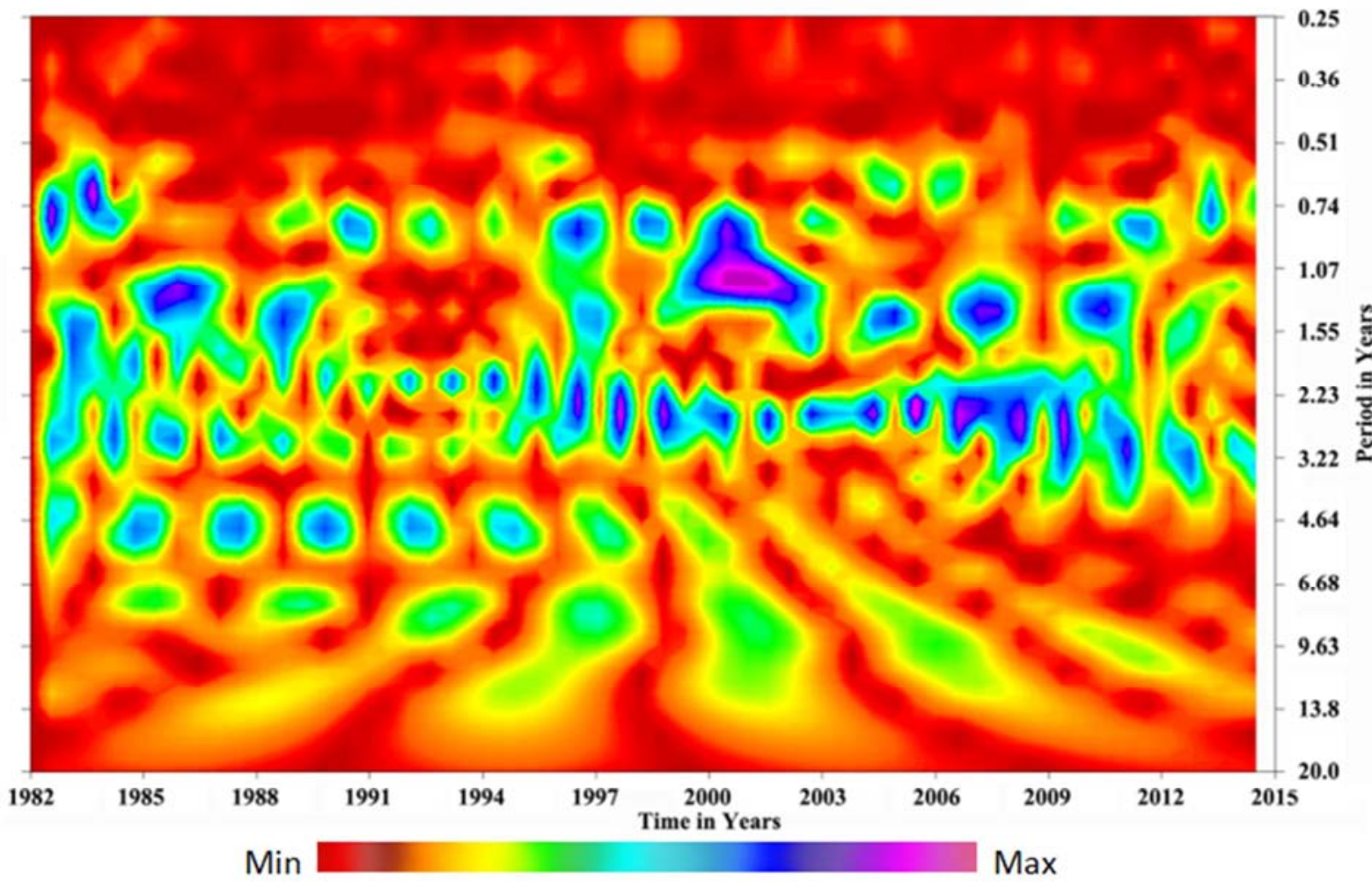

(b)

Figure 13. (a) shows a detailed comparison between the classification results of EP and CP Niño events by Yu and Kim (2013) and by this study. Yellow shade means the EP warming rate is higher than CP warming rate and the blue shade means the CP warming rate is higher than the EP warming rate. The warming rate is calculated by $\triangle C P / \triangle m o n t h$ or $\triangle E P / \Delta m o n t h s$ and the difference is $\triangle E P / \Delta m o n t h s-\triangle C P / \Delta m o n t h s$. (b) shows the continuous wavelet (Morlet) spectrum(in magnitudes) patterns of the blue lines (the warming rate difference) in (a).

\section{Conclusions}

The nature of the $\mathrm{EP}_{R . J \text {. }}$ and $\mathrm{CP}_{\text {R.J. }}$. indices from Ren and Jin's scheme was studied and results show that the low correlation between them reflects the low correlation between the right sides of Equ. (6). This feature indicates that this low correlation is not indicative of the total independence between the CP and EP type El Niño events. Actually the $\mathrm{EP}_{R . J .}$ and $\mathrm{CP}_{R . J}$. indices could not correctly represent the physical details of the Niño events' evolution or transitioning, and therefore their scheme needs further improvements.

This study proposes a new version of the CP and EP Niño region definition according to the SSTA fitting coefficient distributions to the thermal centroid anomaly of the UNR. The UNR are separated into two parts: the central Pacific part and the eastern Pacific part. The new CP and EP indices based on the new Niño regions show that these two types of El Niño events are highly correlated. However, their differences are somewhat independent from the mean SSTA of the UNR. The record of data used here shows that the independent feature group about the El Niño events is between the mean SSTA of the Niño regions and the CP/EP difference (the SSTA gradient along the equator), and not between the $\mathrm{CP}$ and $\mathrm{EP}$ indices themselves. The $\mathrm{CP}$ and $\mathrm{EP}$ region warming rate competition in these two regions has great effects on the El Niño evolutions and characteristics. Actually, the warming rate competition between the $\mathrm{CP}$ and $\mathrm{EP}$ regions can be also regarded as an intrinsic oscillation mode of the El Niño events. It is found that, most of the El Niño events began with a high $\mathrm{CP}$ warming rate, which partly explains the high correlation between the CP/EP events and their co-existence.

The UNR show the greatest SSTA variability across the global ocean, which also covers most of the traditional Niño regions. The $\mathrm{CP}$ and $\mathrm{EP}$ regions in UNR suggested by this study are not necessarily the best choice. Since the literature lacks an accurate and natural definition of the Niño regions, the author believes that discussions presented on the independence or interaction about the two types of El Niño events could contribute to our scientific knowledge.

Because the UNR is defined based on the SST variations along the Pacific Ocean equator, the UNR could be subject to variations when a different period is analyzed, even though this region appeared quite stable in the past sixty years (this result was checked by other data sets and it is not shown here). As a consequence, the CP and EP region definitions appear somewhat independent from the timing selections. Sensitivity tests (not shown here) suggest that, by using the method proposed here, the separating boundaries between the $\mathrm{CP}$ region and the EP region could always be found and stay almost fixed for the past sixty years with only slight variation. The slight variation of the separating boundaries of the $\mathrm{CP}$ and EP regions may reflect the constantly changing nature of the 
El Niño events. Similarly, the fixedness of the traditional rectangular Niño regions may also need a "change". The CP and EP types of ENSO events have been long discussed so far, and they should have their own specific regions properly defined, similar to or different from this study.

\section{Acknowledgements}

This study was jointly supported by National Basic Research Program of China (No. 2012CB957704), National Natural Science Foundation of China (No.40506035 and No.40876005) and an ocean investigation program (PACIND-YGST03, SOA, China). The author thanks NOAA NCEP for providing the sea surface data.

\section{References}

[1] Ashok, K., S. K. Behera, S. A. Rao, H. Weng and T. Yamagata, 2007. El Niño Modoki and its possible teleconnection. J. Geophys. Res. 112, C11007, doi: 10. 1029/2006JC003798.

[2] Banholzer, S., and S. Donner, 2014. The influence of different El Niño types on global average temperature, Geophys. Res. Lett., 41, 2093-2099, doi: 10.1002/2014GL059520.

[3] Bejarano L. and F. F. Jin, 2008. Coexistence of Equatorial Coupled Modes of ENSO. J. Climate, 21, 3051-3067. doi: http://dx.doi.org/10.1175/2007JCLI1679.1

[4] Cai W., A. Santoso, G Wang, S. W. Yeh, S. I. I An, K. Cobb, M. Collins, E. Guilyardi, F. F. Jin, J. S. Kug, M. Lengaigne, M. J. McPhaden, K. Takahashi, A. Timmermann, G. Vecchi, M. Watanabe1 and L. Wu, 2015. ENSO and greenhouse warming. Nature Climate Change. 5, 849-859.

[5] Capotondi, A., A. T. Wittenberg, M. Newman, E. Di Lorenzo, J.-Y. Yu, P. Braconnot, J. Cole, B. Dewitte, B. Giese, E. Guilyardi, F.-F. Jin, K. Karnauskas, B. Kirtman, T. Lee, N. Schneider, Y. Xue, S.-W. Yeh, 2014. Understanding ENSO diversity, Bulletin of the American Meteorological Society, doi: http: 10.1175/BAMS-D-13-00117.1.

[6] Deser, C., M. A. Alexander, S.-P. Xie and A. S. Phillips, 2010. Sea Surface Temperature Variability: Patterns and Mechanisms. Annual Review of Marine Science, Vol. 2: 115 -143.

[7] Fang, Mingqiang, 2006. A thermal centroid or a mass centroid? J. Oceanography, Vol. 62 (No. 5): 759-766.

[8] Fang Mingqiang, Yan Chen, Hongping Li, Lixin Wu, 2013. Surface thermal centroid anomaly of the eastern equatorial Pacific as a unified Niño index. CJOL, Vol. 31 (No. 5), pp1129-1136.

[9] Guckenheimer J., A. Timmermann, H. Dijkstra, and A. Roberts, 2017. (Un)predictability of strong El Niño events. Climate System DOI: 10.1093/climsys/dzx004/467521.

[10] Kao, H. Y. and J. Y. Yu, 2009. Contrasting Eastern-Pacific and Central-Pacific types of ENSO. J. Clim. 22: 615-632.

[11] Kug, J. S., F. F. Jin and S. I. An, 2009. Two types of El Niño events: cold tongue El Niño and warm pool El Niño. J. Clim. 22: $1499-1515$

[12] Kug, J.-S., J. Choi, S.-I. An, F.-F. Jin, and A. T. Wittenberg,
2010. Warm pool and cold tongue El Niño events as simulated by the GFDL CM2.1 coupled GCM. J. Climate, 23, 1226-1239. doi: 10.1175/2009JCLI3293.1

[13] Larkin, N. K. and D. E. Harrison, 2005. Global seasonal temperature and precipitation anomalies during El Niño autumn and winter. Geophys. Res. Lett. 32, L13705, doi: $10.1029 / 2005$ GL022738.

[14] Latif, M., R. Kleeman and C. Eckert, 1997. Greenhouse warming, decadal variability, or El Niño? An attempt to understand the anomalous 1990s. J. Clim. 10: 2221-2239.

[15] McPhaden, M. J., T. Lee, and D. McClurg, 2011. El Niño and its relationship to changing background conditions in the tropical Pacific Ocean, Geophys. Res. Lett., 38, L15709, doi: 10.1029/2011GL048275.

[16] Paek, H., J.-Y. Yu, and C. Qian, 2017. Why were the 2015/2016 and 1997/1998 extreme El Niños different? Geophys. Res. Lett., 44, doi: 10.1002/ 2016GL071515.

[17] Peng Jingbei, Zhang Qingyun, and Chen Lieting, 2011. Connections between different types of El Niño and Southern/Northern Oscillation. Acta Meteor. Sinica, 25(4), 506-516, doi: 10. 1007/s13351-011-0409-9.

[18] Ren, H. L., and F. F. Jin, 2011. Niño indices for two types of ENSO, Geophys. Res. Lett., 38, L04704, doi: 10.1029/2010GL046031.

[19] Ren H. L, F. F. Jin, M. F. STUECKER and R. H. Xie, 2013. ENSO Regime Change since the Late 1970s as Manifested by Two Types of ENSO. Journal of the Meteorological Society of Japan, Vol. 91, No. 6, pp. 835842, DOI: 10.2151/jmsj.2013-608.

[20] Reynolds, R. W., 1988. A real-time global sea surface temperature analysis. J. Clim., 1: 75-86.

[21] Reynolds, R. W. and D. C. Marsico, 1993. An improved real-time global sea surface temperature analysis. J. Clim., 6: 114-119.

[22] Reynolds, R. W. and T. M. Smith, 1994. Improved global sea surface temperature analyses. J. Clim., 7: 929-948.

[23] Takahashi K. and B. Dewitte, 2015. Strong and moderate nonlinear El Niño regimes. Clim. Dyn., DOI 10.1007/s00382-015-2665-3.

[24] Takahashi, K., A. Montecinos, K. Goubanova, and B. Dewitte, 2011. ENSO regimes: Reinterpreting the canonical and Modoki El Niño. Geophys. Res. Lett., 38, L10704, doi: 10.1029/2011GL047364.

[25] Trenberth K. E., 1984. Signal versus noise in the Southern Oscillation. Mon Weather Rev. 112: 326-332. Trenberth, K. E., 1997. The definition of El Niño. Bull. Amer. Meteor. Soc. 78: 2771-2777.

[26] Trenberth, K. E. and D. P. Stepaniak, 2001. Indices of El Niño Evolution. J. Clim., 14: 1697-1701.

[27] Trenberth, K. E. and L. Smith, 2006. The vertical structure of temperature in the tropics: Different flavors of El Niño. J. Climate, 19, 4956-4973.

[28] Xiang, B. Q., B. Wang, and T. Li, 2012. A new paradigm for the predominance of standing Central Pacific Warming after the late 1990s. Clim. Dyn., doi: 10.1007/s00382-012-1427-8. 
[29] Yeh, S. W., J. S. Kug, B. Dewitte, M.-H. Kwon, B. P. Kirtman and F.-F. Jin, 2009. El Niño in a changing climate, Nature. 461: 511-514.

[30] Yu, J. Y., H. Y. Kao, T. Lee and S. T. Kim, 2011. Subsurface ocean temperature indices for Central-Pacific and Eastern-Pacific types of El Niño and La Niña events. Theor. Appl. Climatol. 103: 337-344. DOI 10.1007/s00704-010-0307-6.
[31] Yu, J.-Y. and Kim, S. T., 2013. Identifying the types of major El Niño events since 1870. Int. J. Climatol., 33: 2105-2112. doi: 10.1002/joc.3575.

[32] Zheng, F., X.-H. Fang, J.-Y. Yu and J. Zhu. 2014. Asymmetry of the Bjerknes positive feedback between the two types of El Niño, Geophys. Res. Lett., 41, doi: 10.1002/2014GL062125. 